\title{
Atrioventricular Dissociation by ECG Finding
}

National Cancer Institute

\section{Source}

National Cancer Institute. Atrioventricular Dissociation by ECG Finding. NCI Thesaurus. Code $C 71045$.

An electrocardiographic finding in which the electrical activity of the atria and ventricles are independent of one another. (CDISC) 